\title{
Significados da dinâmica familiar por homens que reproduziram a violência doméstica
}

Meanings of family dynamics by men who reproduced domestic violence Significado de la dinámica familiar por hombres que reprodujeron la violencia doméstica

Júlia Renata Fernandes de Magalhães ${ }^{1}$ (iD https://orcid.org/0000-0003-0631-2374

Nadirlene Pereira Gomes ${ }^{1}$ io https://orcid.org/0000-0002-9466-0936

Fernanda Matheus Estrela ${ }^{2}$ id https://orcid.org/0000-0001-7501-6187

Andrey Ferreira da Silva ${ }^{1}$ id https://orcid.org/0000-0002-1038-7443

Milca Ramaiane da Silva Carvalho ${ }^{3}$ io https://orcid.org/0000-0002-6571-3437

Álvaro Pereira ${ }^{1}$ io https://orcid.org/0000-0003-1899-7374

Moniky Araújo da Cruz ${ }^{1}$ io https://orcid.org/ 0000-0003-2955-5408

Jordana Brock Carneiro ${ }^{1}$ io https://orcid.org/0000-0002-7496-852X

\section{Como citar:}

Magalhães JR, Gomes NP, Estrela FM, Silva $A F$, Carvalho MR, Pereira A, et al. Significados da dinâmica familiar por homens que reproduziram a violência doméstica. Acta Paul Enferm. 2021;34:APE00803.

DOI

http://dx.doi.org/10.37689/actaape/2021A000803

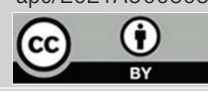

Descritores

Violência doméstica; Criança; Homens; Interacionismo simbólico; Relações familiares

Keywords

Domestic violence; Child; Men; Symbolic interactionism; Family relations

Descriptores

Violencia doméstica; Niño; Hombre; Interaccionismo simbólico; Relaciones familiares

Submetido

13 de Abril 2020

Aceito

20 de Agosto de 2020

Autor correspondente

Júlia Renata Fernandes de Magalhães E-mail: julinha_cte@hotmail.com

\section{Resumo}

Objetivo: Analisar os significados atribuídos à dinâmica familiar por homens que reproduziram a violência doméstica vivenciada na infância.

Métodos: Trata-se de uma pesquisa qualitativa guiada à luz do Interacionismo Simbólico. Procurou-se conhecer a história oral de homens em processo jurídico junto à $2^{\text {a }}$ Vara de Justiça pela Paz em Casa, situada no município de Salvador, Bahia, Brasil. Para tanto, utilizou-se entrevistas, as quais foram transcritas, textualizadas e transcriadas. A organização dos dados se deu com base na Análise de Conteúdo Temática.

Resultados: As narrativas revelam que a interpretação das experiências de agressões físicas, psicológicas, negligência e testemunho da violência conjugal entre os pais na infância direcionou a construção dos significados de que a dinâmica familiar deve ser pautada no controle e dominação masculina sobre a esposa e filhos, princípios que nortearam os relacionamentos familiares na fase adulta.

Conclusão: As histórias remetem para o significado de que a dinâmica familiar deve ser delineada com base na divisão sexual dos papéis, sendo o homem considerado o provedor e autoridade máxima da casa e a mulher responsável pelo cuidado dos filhos. Nota-se ainda a simbologia de que a interação entre pai e filhos deve ser estabelecida de maneira rude e severa. Estes significados predispõem à reprodução da violência durante a vida adulta, o que demonstra a importância de ações que viabilizem a ressignificação das interações familiares violentas, preferencialmente ainda na fase da infância.

\section{Abstract}

Objective: To analyze the meanings attributed to family dynamics by men who reproduced domestic violence suffered in their childhood.

Methods: This is a qualitative research guided in the light of Symbolic Interactionism. We sought to know the oral history of men under criminal prosecutions before the $2^{\text {nd }}$ Court of Justice for Peace at Home, located in the city of Salvador, Bahia, Brazil. To this end, interviews were used, which were transcribed, textualized and transcribed. Data organization was based on content analysis.

Results: The statements reveal that interpreting physical, psychological aggression, neglect and witness of domestic violence experiences between parents in childhood directed constructing the meanings that family dynamics must be based on male control and domination over the wife and children, principles that guided family relationships in adulthood.

Conclusion: The stories refer to the meaning that family dynamics must be delineated based on sexual division of roles, with men being considered providers and maximum authority of the house, and women, responsible

'Universidade Federal da Bahia, Salvador, BA, Brasil.

2Universidade Estadual de Feira de Santana, Feira de Santana, BA, Brasil.

3Universidade do Estado da Bahia, Senhor do Bomfim, BA, Brasil.

Conflitos de interesse: nada a declarar. 
for children care. It is also noted the symbology that father-children interaction must be established in a rude and severe way. These meanings predispose to reproducing violence during adulthood, which demonstrates the importance of actions that make it possible to redefine violent family interactions, preferably still in childhood.

\section{Resumen}

Objetivo: Analizar el significado atribuido a la dinámica familiar por hombres que reprodujeron la violencia doméstica vivida en la infancia.

Métodos: Se trata de un estudio cualitativo guiado según el interaccionismo simbólico. Se buscó conocer la historia oral de hombres en proceso judicial en el $2^{\circ}$ Tribunal de Justica por la Paz en Casa, situado en el municipio de Salvador, estado de Bahia, Brasil. Para eso, se utilizaron entrevistas que fueron transcriptas, textualizadas y transcreadas. La organización de los datos se realizó con base en el análisis de contenido temático.

Resultados: Las narrativas revelan que la interpretación de las experiencias de agresiones físicas, psicológicas, negligencia y testigo de la violencia conyugal entre los padres en la infancia llevó a la elaboración del significado de que la dinámica familiar debe estar marcada por el control y dominación masculina sobre la esposa e hijos, principios que guían las relaciones familiares en la fase adulta.

Conclusión: Las historias remiten al significado de que la dinámica familiar debe estar definida con base en la división sexual de los roles, en que el hombre es considerado proveedor y autoridad máxima de la casa y la mujer responsable del cuidado de los hijos. Además, se observó la simbología de que la interacción entre padre e hijo debe establecerse de forma grosera y severa. Estos significados predisponen a la reproducción de la violencia durante la vida adulta, lo que demuestra la importancia de acciones que posibiliten la resignificación de las intervenciones familiares violentas, preferentemente aún en la fase de la infancia.

\section{Introdução}

Em todo o mundo, os dados de crianças em situação de violência são preocupantes, em especial quando esta se dá no processo de interação intrafamiliar. Levantamento mundial estima que cerca de $300 \mathrm{mi}$ lhões de crianças sejam submetidas a agressóes físicas e/ou psicológicas pelos pais ou outros cuidadores em casa. ${ }^{(1)}$ No Brasil, somente no ano de 2018, foram reportados a um canal telefônico de denúncias mais de 76 mil casos. ${ }^{(2)}$ Esta realidade, cujos percentuais não retratam o número real de vítimas devido ao caráter velado dos abusos domésticos, ${ }^{(3)}$ demanda por estratégias de proteção a este público.

Um cotidiano familiar permeado pela violência traz repercussóes para a saúde e desenvolvimento humano. Estudo realizado na Coreia do Sul aponta que as crianças que residem em lares violentos tendem a apresentar depressão e ansiedade, além de comportamentos agressivos e delinquentes. ${ }^{(4)}$ No Texas, investigação com jovens revela associação positiva entre agressão física na infância e perpetração no namoro. ${ }^{(5)}$ Corroborando, pesquisa brasileira mostrou que homens, por presenciarem relaçóes conflituosas entre seus pais na infância, tendem a perceber a violência como algo natural e reproduzir este comportamento. ${ }^{(6)}$

Relevante pontuar que a família tem função social de proteger, cuidar e transmitir afeto às crianças, de modo a proporcionar seu pleno desenvolvimento. ${ }^{(7)}$ Todavia, imersos no contexto de abusos familiares, tais prerrogativas vêm sendo violadas, o que requer aten- ção por parte dos profissionais, sobretudo que atuam na área da saúde, social e da educação, no sentido de assegurar aos indivíduos uma infância e adolescência "livre de qualquer forma de negligência, discriminação, exploração, violência, crueldade e opressão". (7)

Considerando que a família configura-se enquanto sistema normatizador das relações entre os indivíduos, infere-se que crianças com história de violência intrafamiliar tendem a reproduzi-la em relacionamentos futuros. ${ }^{(3)}$ Assim, partindo do pressuposto de que as ações são mediadas por significados construídos a partir das interaçôes sociais anteriores, ${ }^{(8)}$ acredita-se que os significados atribuídos por homens à dinâmica familiar vivenciada na infância influenciem na maneira como se conformam os seus relacionamentos familiares na vida adulta. Compreendendo que para intervir nas relaçóes familiares pautadas na violência, se faz necessário modificar a interpretaçáo dos símbolos e favorecer a construção de novos significados, questiona-se: Como homens em processo jurídico por violência conjugal significam a dinâmica familiar vivenciada na infância?

Nesta perspectiva, o estudo objetiva analisar os significados atribuídos à dinâmica familiar por homens que reproduziram a violência doméstica vivenciada na infância.

\section{Métodos}

Trata-se de uma pesquisa qualitativa guiada à luz do Interacionismo Simbólico, o qual se baseia em 
três premissas: o ser humano age com base nos significados que as coisas têm para ele; os significados se originam da interação social estabelecida com as outras pessoas; e tais significados podem ser modificados através do processo interpretativo elaborado pelo indivíduo ao defrontar-se com diferentes situaçôes em seu caminho. ${ }^{(8)}$

Tendo em vista que os significados atribuídos à dinâmica familiar na infância podem influenciar na maneira como se delineia a interação familiar na fase adulta, procurou-se conhecer a história oral de homens em processo jurídico junto à 2a Vara de Justiça pela Paz em Casa, situada no município de Salvador, Bahia, Brasil. Os critérios de inclusão foram: estar em processo jurídico por violência conjugal e ter experienciado ou testemunhado violência intrafamiliar na infância. Foram excluídos àqueles instáveis emocionalmente segundo avaliação realizada pela psicóloga do serviço, totalizando 05 participantes.

A aproximação com os colaboradores ocorreu através de Grupos Reflexivos com Homens desenvolvidos com o propósito de prevenir e enfrentar o fenômeno da violência conjugal. Com o desenvolver das dinâmicas, foi possível identificar os participantes que atendiam aos critérios de inclusão, os quais foram contactados via telefone e convidados a participar da pesquisa. $\mathrm{O}$ número de participantes não foi definido previamente, uma vez que se optou pelo caminho metodológico da História Oral, que prioriza o aprofundamento dos discursos, em detrimento do quantitativo de sujeitos. ${ }^{(9)}$

Foram atendidas as recomendaçóes nacionais e internacionais de pesquisas envolvendo seres humanos, conforme resolução do conselho nacional de saúde n. 466/2012, além de seguidos os critérios do COREQ. O estudo recebeu parecer aprovado ( $\mathrm{n}^{\mathrm{o}}$ 2.639.224) pelo Comitê de Ética em Pesquisa da Universidade Federal da Bahia em 19/11/2014.

Para conhecer a História Oral dos participantes, utilizou-se a técnica da entrevista guiada por um roteiro semi-estruturado contemplando aspectos sociodemográficos e a seguinte questão norteadora: Conte-me como era a sua relaçáo familiar na infância e como tem sido atualmente. A coleta dos dados ocorreu individualmente, no período de abril a ju- lho de 2018, em locais previamente acordados com os homens, dentre eles, a sala do grupo de pesquisas e o próprio domicílio dos participantes, porém, sem a presença dos familiares.

As entrevistas foram gravadas em áudio e tiveram duração média de duas horas e trinta minutos. Para a sistematização, inicialmente realizou-se a transcrição na íntegra de todo o conteúdo oral, em seguida, foram realizadas as seguintes etapas: textualização (organização do discurso na primeira pessoa do singular, sendo excluídos os elementos desnecessários); e transcriação (organização lógica do texto). ${ }^{(9)}$

Após esse processo, o material reorganizado foi apresentado aos participantes, os quais conferiram o conteúdo e assinaram a carta de cessão de direitos. Procedeu-se então a organização das narrativas com base na Análise de Conteúdo Temática, contemplando as seguintes etapas: pré-análise; exploração do material; tratamento dos resultados e interpretação. ${ }^{(10)}$ Após leitura exaustiva do conteúdo, foram identificados os discursos relacionados com cada tema eixo, emergindo as categorias analíticas, cujos achados foram interpretados à luz do interacionismo simbólico. Ressalta-se que o processo de categorização foi viabilizado pelo software $\mathrm{NVIVO}^{\circledR} 11$, criado para favorecer a organização de dados qualitativos, e que durante a análise dos discursos foi realizada a checagem por pares, evitando assim, vieses de interpretação.

\section{Resultados}

Foram entrevistados cinco homens em processo jurídico por violência conjugal junto à 2a Vara de Justiça pela paz em casa do município de Salvador, Bahia, Brasil. Estes tinham faixa etária entre 27 a 41 anos e se autodeclararam pardos. No que se refere à religião, três informaram ser católicos, um evangélico e um espírita. Quanto à escolaridade, dois possuíam nível superior completo e três o ensino médio completo. A renda variou entre mil e cem reais a dez mil reais. Todos relataram estar solteiros e terem rompido com a parceira autora da denúncia de violência. 
Quadro 1. Significados atribuídos à dinâmica familiar por homens que reproduziram a violência doméstica vivenciada na infância

\begin{tabular}{|c|c|c|}
\hline \multicolumn{3}{|c|}{ Dinâmica familiar } \\
\hline Experiência na infância & Significado & Experiência na fase adulta \\
\hline $\begin{array}{l}\text { Meu padrasto era um homem rude, que sempre falava de forma ríspida e agressiva } \\
\text { comigo. Eu era uma criança que não podia fazer nada. Ele me proibia de sair de } \\
\text { casa, brincar com outras crianças. Por qualquer coisa, ele brigava e gritava comigo. } \\
\text { (H1) }\end{array}$ & $\begin{array}{l}\text { O pai deve ser rude } \\
\text { com os filhos }\end{array}$ & $\begin{array}{l}\text { Eu não gostava que meus filhos brincassem na rua e nem tivessem muitas amizades. } \\
\text { Também não sou muito de conversa. Falo só uma vez. Nisso, eu sou igual a meu pai: } \\
\text { acho que filho deve ser criado na rédea curta, mesmo que eles me achem grosseiro. } \\
\text { (H1) }\end{array}$ \\
\hline $\begin{array}{l}\text { Eu cresci em um lar violento! Meu pai era o dono da razão e ninguém podia } \\
\text { questionar as atitudes tomadas por ele. Sempre que se desentendiam, ele batia em } \\
\text { minha mãe. Já a gente (filhos), apanhava e ficava de castigo. (H2) }\end{array}$ & $\begin{array}{l}0 \text { esposo/pai não } \\
\text { deve ser questionado }\end{array}$ & $\begin{array}{l}\text { Eu não admito que a minha mulher ou que os filhos me respondam. Por isso, quando } \\
\text { isso acontecia eu acabava sendo agressivo ao ponto de bater nela e castigar meus } \\
\text { filhos. (H2) }\end{array}$ \\
\hline $\begin{array}{l}\text { Na infância, presenciei muitas brigas entre meus pais. A maioria delas era porque } \\
\text { meu pai não queria que minha mãe tivesse relações de amizade. Sempre queria } \\
\text { saber para onde ela ia e quem iria junto. Ele não gostava que ela saísse nem com } \\
\text { as irmãs dela. (H3) }\end{array}$ & $\begin{array}{l}\text { O esposo deve } \\
\text { controlar } 0 \text { convívio } \\
\text { social da mulher }\end{array}$ & $\begin{array}{l}\text { Eu sempre monitorava o celular e as amizades da minha mulher. [...] ficava imaginando } \\
\text { que as pessoas poderiam, de alguma forma, influenciar em nossa relação. (H3) }\end{array}$ \\
\hline $\begin{array}{l}\text { Sempre que minha mãe descobria alguma traição, eles acabavam brigando e } \\
\text { ela era espancada. Chegamos, inclusive, a presenciar ele a esfaqueando. Apesar } \\
\text { de tudo, ela sempre o perdoava e voltavam a morar juntos como se nada tivesse } \\
\text { acontecido. (H4) }\end{array}$ & $\begin{array}{l}0 \text { esposo pode } \\
\text { ter relações } \\
\text { extraconjugais }\end{array}$ & $\begin{array}{l}\text { Mesmo estando com ela, tive vários outros relacionamentos. Quando ela descobria, } \\
\text { vinha tirar satisfações e me pressionava a assumir a traição. A gente discutia muito por } \\
\text { causa disso e eu perdia a paciência. Âs vezes, resultava em agressão física porque eu } \\
\text { a empurrava ou até batia para ela me deixar em paz. Minha mãe sempre perdoou as } \\
\text { traições de meu pai, então ela deveria me perdoar também. (H4) }\end{array}$ \\
\hline $\begin{array}{l}\text { Meu pai trabalhava o dia todo e minha mãe ficava em casa, mas não cuidava de } \\
\text { mim e nem dos meus irmãos. Ela não limpava a casa, não cozinhava e nem dava } \\
\text { banho na gente. Quando o meu pai chegava do trabalho e via aquela situação eles } \\
\text { discutiam. (H5) }\end{array}$ & $\begin{array}{l}0 \text { esposo deve } \\
\text { prover o lar e a } \\
\text { esposa cuidar da } \\
\text { casa e dos filhos }\end{array}$ & $\begin{array}{l}\text { A gente brigava muito porque eu chegava do trabalho e encontrava minha filha suja. } \\
\text { [...] eu a chamava de irresponsável, porca, largada, vagabunda. Já cheguei a empurrá- } \\
\text { la algumas vezes. Eu exigia que ela cuidasse direito da nossa filha e da casa. (H5) }\end{array}$ \\
\hline
\end{tabular}

A História Oral apontou para a vivência de uma infância permeada por agressóes físicas, psicológicas, negligência, além do testemunho da violência conjugal entre os pais. A interpretação dessas experiências, por sua vez, direcionou a construção dos significados de que a dinâmica familiar deve ser delineada no sentido de que o homem seja rude com os filhos, inquestionável, detenha o controle sobre o convívio social da mulher, possua permissão social para ter relaçóes extraconjugais, além de ser o provedor do lar, enquanto a esposa, a responsável pelo cuidado da casa e dos filhos. Com base nesses significados foram estabelecidos os padróes de relacionamentos familiares na fase adulta (Quadro 1).

\section{Discussão}

O estudo permitiu desvelar que, no processo de interação no ambiente doméstico, os homens, ainda na infância, apreendem símbolos e significados inerentes à dinâmica familiar, ao redor dos quais, significam os papéis sociais que homens e mulheres deverão assumir ao longo da vida. Um destes significados remete aos atributos, bem definidos, que delimita os espaços de atuação entre os gêneros, de modo a naturalizar a divisão social na esfera pública, destinada aos homens, e no doméstico, inerente às mulheres. Frente a esta experiência, reproduziram o significado de que lhes é conferida a obrigatorieda- de de prover o sustento da família enquanto que as mulheres devem responsabilizar-se pelo cuidado da casa e dos filhos.

Essa conjuntura foi questionada intensamente na década de 70, no contexto do movimento feminista, diante reivindicaçóes por seus direitos, em especial por igualdade nas condiçóes de trabalho, salários e também na divisão das tarefas domésticas. Dentre as conquistas, as mulheres passam então a ocuparem espaços e papéis antes atribuídos aos homens, a exemplo do sustento da casa. ${ }^{(11)}$ Todavia, tal fato não trouxe a ressignificação masculina dos significados que permeiam o espaço tido como das mulheres. ${ }^{(12)}$

Assim, diferentemente do papel de prover a casa, que atualmente com mais de 28 milhóes de famílias brasileiras chefiadas por mulheres, ${ }^{(13)}$ às funçóes sociais do cuidado com a casa e filhos, por exemplo, não apresentaram a mesma transformação, com tímida participação de homens nas tarefas domésticas, a qual, na maioria das vezes, se dá como forma de "ajuda" (14) Enraizada na função biológica de gestar e amamentar, esses papéis ainda são acentuadamente desempenhados por mulheres, persistindo a desigualdade de gênero, que culmina em sobrecarga de trabalho feminino. ${ }^{(15)}$ Essa realidade, apreendida nos modelos familiares dos entrevistados e reproduzida na relação familiar atual, evidencia a falta de consciência dos homens quanto a responsabilidade na divisão de tarefas domésticas, sobretudo de cuidado e educação dos filhos. 
Entretanto, indo ao encontro da reconstrução dos papéis sociais, existe um movimento no qual alguns homens ressignificam seu papel e delineiam sua subjetividade de esposo/pai com novos significados. Mesmo que de forma lenta, progressivamente, é identificável na sociedade homens que incorporam a figura contemporânea de esposo/pai em suas corporalidade e afetividade, assumindo, entre outras açóes, o cuidado da casa e filhos. ${ }^{(16)}$

Contudo, no caso dos entrevistados, o estudo desvela uma infância permeada pela ausência de afetividade paterna e expressa por meio do uso de palavras rudes, falta de diálogo e inibição da interação com outras crianças. Sobre esta última, salienta-se que o controle dos relacionamentos interpessoais, expresso na proibição de sair de casa para brincar com outras crianças, inviabiliza a reflexão e reconstrução de experiências vivenciadas nos espaços familiares, cenário prejudicial ao desenvolvimento infantil. ${ }^{(17)}$ Diante disso, perde-se o espaço comunitário de interação, consubstancial para reflexão das experiências na relação familiar, restando ao espaço escolar à aprendizagem de outros significados às relaçóes sociais masculinas. ${ }^{(18)}$ Ademais, a ausência da referência de afeto na relação pai-filho é elemento direcionador a prejuízos no desenvolvimento infantil e, quando permeado pela violência, amplifica ainda mais as repercussóes de cunho físico e psicológico. ${ }^{(3,19)}$

Independentemente do entendimento acerca da importância do brincar para o processo de desenvolvimento das crianças, o contexto familiar permeado pela falta de diálogo, falas ríspidas e discussóes remete à criança a crença de que a relação pai-filho deve se estabelecer da mesma maneira. Neste cenário, é importante que homens que vivenciaram a fragilidade da relação pai-filho na infância, ao viver a experiência do Ser Pai, rompam os estereótipos do passado, compreendido como ser provedor e hostil, e abram possibilidades de espaços para o cuidado, o diálogo, a emoção e o afeto. ${ }^{(20)}$ É necessário que, mesmo diante de uma figura paterna severa e autoritária, experiência vivenciada na infância pelos participantes deste estudo, os homens tenham oportunidade de modificar os símbolos apreendidos, o que favorecerá comportamento mais tolerante e afetuoso na relação familiar. Estudo realizado na Indonésia aborda que relaçóes afetuosas com o pai podem reduzir o comportamento agressivo dos filhos, o que aponta para a importância do elo familiar na formação infantil. ${ }^{(18)}$

Outro significado desvelado, a partir das narrativas, remete ao entendimento de que o esposo/ pai não deve ser questionado. Para os entrevistados, compete aos homens o dever de reger a família por meio dos seguintes princípios: as esposas estão hierarquicamente subordinadas ao marido; e os filhos, subordinados ao pai, de modo que esposa e filhos não podem contestar o esposo/pai. Essa concepção é corroborada em estudo realizado na Escócia com jovens que afirmam que a definição do papel de chefe para os homens se estabelece de maneira tão clara que qualquer questionamento de suas atitudes não é aceitável, podendo, inclusive, utilizar da violência na tentativa de se afirmar enquanto possuidor da razão. ${ }^{(21)}$ Assim, no contexto familiar, os homens aprendem que a mulher e os filhos devem submeter-se a autoridade masculina, expressa na tomada de decisão em relação às determinações domésticas.

Dessa forma, os homens assimilam, desde a infância, não só a forma de se relacionar com os filhos, mas também o direito de decidir sobre a vida de suas companheiras e, assim, o controle destas. ${ }^{(22)}$ A naturalização da autoridade masculina, reforçada pelo ideal de que a mulher deve ser submissa ao homem e de que este detém o direito de controlá-la, também foi desvelada no estudo, ilustrada nas falas que remetem ao controle do convívio social. Os homens percebiam, ainda quando crianças, que um dos motivos dos conflitos conjugais entre os pais remetia a privação da liberdade das mulheres, em especial quanto ao direito de ir e vir e as relaçóes de amizades. A partir destas experiências na infância, apreenderam os significados e reproduziram comportamentos semelhantes quando adultos.

Essa convicção, socialmente compartilhada, de que o homem deve controlar a mulher impóem-se como uma necessidade masculina, estando permeada pelo ideal de hierarquia conjugal e pelas atribuições do papel feminino na relação conjugal enquanto esposa cuidadora e fiel, dedicada exclusivamente à maternidade e ao lar. ${ }^{(23)}$ No que tange ao cerceamento da liberdade feminina, esta pode ser justi- 
ficada pelo receio de interferências de terceiros no relacionamento, conforme assinala estudo desenvolvido com mulheres que vivenciaram violência. ${ }^{(24)}$

Ao assumir relaçóes extraconjugais, os homens deste estudo desvelam que, a partir da relação dos pais, naturalizaram tal comportamento como inerente aos homens, sendo, portanto, esperado concordância da mulher. Inclusive, estudo desenvolvido na Columbia acrescenta que os relacionamentos extraconjugais dos homens conferem a eles títulos sociais de virilidade. ${ }^{(25)}$ Diferentemente, no que diz respeito à construção social da fidelidade feminina, quando as mulheres não correspondem a esta obrigação, os homens tendem a adotar comportamento agressivo, sendo durante anos legitimado o assassinato feminino em nome da honra. ${ }^{(26)}$ Ancorado na desigualdade de gênero, essa permissividade para o homicídio da mulher, tido como adúltera, alimentava seu rebaixamento social, o sentimento de ódio e a aplicação da violência. ${ }^{(27)}$

Importante ressaltar que os significados abstraídos da vivência de homens que, na infância, presenciaram relaçóes familiares pautadas na violência, acabam por contribuir para a naturalização do poder masculino, reforçando a assimetria social entre os gêneros que, por sua vez, acirra a constância do fenômeno da violência doméstica. Para a transformação desta realidade, os profissionais de saúde, da educação e ação social são essenciais visto que, para além de favorecer a identificação de crianças em situação de abusos familiares, poderão promover açôes pautadas no diálogo, respeito e compartilhamento de tarefas e poderes entre os gêneros, de modo a possibilitar a apreensão de novos símbolos e sentidos capazes de transformar a dinâmica familiar futura. Nesse ínterim, o Programa Saúde na Escola (PSE) se apresenta enquanto instrumento importante nesse processo pelo potencial de atuação junto a crianças e adolescentes. ${ }^{(3)}$

Embora o estudo limite-se por representar os discursos de um grupo reduzido de homens inseridos em determinado contexto cultural do nordeste brasileiro, não permitindo a generalização dos achados, bem como por não apreender a simbologia da dinâmica familiar atribuída por homens cuja infân- cia não fora marcada por relaçôes de violência, os resultados contribuem para a atuação da enfermagem e demais ciências da saúde ao possibilitar maior compreensão dos significados potencialmente maléficos para o desenvolvimento do ser-homem-esposo-pai. As narrativas oferecem elementos para que os profissionais da saúde reflitam acerca da importância de estratégias educativas a serem implementadas, o mais precocemente, junto às crianças no sentido de viabilizar a construção de símbolos familiares pautados na afetividade, respeito e simetria entre os gêneros.

\section{Conclusão}

As narrativas de homens em processo criminal por violência conjugal revelam que a interpretação das experiências familiares vivenciadas na infância conduziu a construção dos significados de que a dinâmica familiar deve ser pautada no controle e dominação masculina sobre a esposa e filhos. As falas remetem para a compreensão de que o sistema familiar deve ser organizado com base na divisão sexual dos papéis, sendo o homem considerado o provedor e autoridade máxima da casa e a mulher responsável pelo cuidado dos filhos. Os discursos demonstram ainda a simbologia de que a interação entre pai e filhos deve ser delineada de maneira rude e severa. Estes significados predispóem a reprodução da violência durante a vida adulta e perpetuação desse fenômeno na sociedade, o que demonstra a necessidade do desenvolvimento de açôes que viabilizem a ressignificação da dinâmica familiar por homens com história de violência doméstica, preferencialmente ainda na fase da infância.

\section{Colaborações}

Magalhães JRF, Gomes NP, Estrela FM, Silva AF, Carvalho MRS, Pereira A, Cruz MA e Carneiro JB declaram que contribuíram com a concepção do estudo, análise e interpretação dos dados, redação do artigo e aprovação da versão final a ser publicada. 


\section{Referências}

1. United Nations Children's Fund (INICEF). A familiar face: Violence in the lives of children and adolescents [Internet]. New York: UNICEF; 2017 [cited 2020 Jan 1]. 100 p. Available from: https://www.unicef.org/publications/ files/Violence_in_the_lives_of_children_and_adolescents.pdf

2. Ouvidoria Nacional Direitos humanos. Disque Direitos Humanos: Relatório 2018. Brasília - DF: Ministério da Mulher, da Família e dos Direitos Humanos. Ouvidoria Nacional dos Direitos Humanos; 2019 [citado 2020 Mai 18]. Disponível em: https://www.gov.br/mdh/pt-br/ acesso-a-informacao/ouvidoria/Disque_Direitos_Humanos.pdf

3. Carneiro JB, Gomes NP, Estrela FM, Santana JD de, Mota RS, Erdmann $\mathrm{AL}$. Domestic violence: repercussions for women and children. Esc Anna Nery. 2017 21(4): e20160346.

4. Cho M. A Study on the psycho-social disturbance of children who are exposed to domestic violence: focusing on hierarchical analysis verification. Asia-pacific J Converg Res Interchang. 2018; 4(3):31-42.

5. Temple JR, Choi HJ, Reuter T, Wolfe D, Taylor CA, Madigan S, et al. Childhood corporal punishment and future perpetration of physical dating violence. J Pediatr. 2018;194:233-7.

6. Paixão GP, Pereira A, Gomes NP, Sousa AR de, Estrela FM, Silva Filho UR, et al. Naturalization, reciprocity and marks of marital violence: male defendants' perceptions. Rev Bras Enferm. 2018;71(1): 178-84.

7. Brasil. Leis, Decretos. Lei no 8.069, de 13 de julho de 1990 (Br). [Internet]. Dispõe sobre o Estatuto da Criança e do Adolescente e dá outras providências. Brasília: Diário Oficial da União; 1990. Disponível em: http://www.planalto.gov.br/ccivil_03/leis/L8069.htm

8. Gadea CA. El interaccionismo simbólico y sus vínculos con los estudios sobre cultura y poder en la contemporaneidad. Sociológica (Méx.). 2018; 33(95): 39-64.

9. Gattaz A, Meihy JC, Seawright L. História oral a democracia das vozes. São Paulo: Pontocom; 2019.

10. Bardin L. Análise de conteúdo. São Paulo: Edições 70; 2016. 280 p.

11. Costa FA. Mulher, trabalho e família: os impactos do trabalho na subjetividade da mulher e em suas relações familiares. Pretextos: Rev Grad Psicol PUC Minas. 2018; 3(6):434-52.

12. Colcerniani CB, D'avila Neto MI, Cavas CS. A participação das mulheres no mercado de trabalho sob a perspectiva da teoria da justiça social de Nancy Fraser e dos conceitos relativos ao trabalho decente. Cad Psicol Soc Trab. 2015; 18(2): 169-80.

13. Cavenaghi $S$, Alves JE. Mulheres chefes de família bi Brasil: avanços e desafios. Rio de Janeiro: ENS-CPES, 2018 [citado 2020 Mai 22]. Disponível em: https://www.ens.edu.br/arquivos/mulheres-chefes-defamilia-no-brasil-estudo-sobre-seguro-edicao-32_1.pdf
14. Costa FA. Mulher, trabalho e família: os impactos do trabalho na subjetividade da mulher e em suas relações familiares. Pretextos. 2018 [citado 2020 Mai 22]; 3(6). Disponível em: http://periodicos. pucminas.br/index.php/pretextos/article/view/15986

15. Ved R, Scott K, Gupta G, Ummer 0, Singh S, Srivastava A, et al. How are gender inequalities facing India's one million ASHAs being addressed? Policy origins and adaptations for the world's largest allfemale community health worker programme. Hum Resour Health. 2019;17(1):3.

16. Bustamante V. Participação paterna no cuidado durante o primeiro ano de vida. Pensando Fam. 2019; 23(1): 89-104.

17. George JST, Fletcher R, Palazzi K. Comparing fathers' physical and toy play and links to child behaviour: an exploratory study. Infant Child Dev. 2017; 26(1): e1958.

18. Dewi KS, Prihatsanti U, Setyawan I, Siswati. Children's aggressive behavior tendency in central java coastal region: the role of parentchild interaction, father's affection and media exposure. Procedia Environ Sci. 2015; 23:192-8.

19. Rani P, Dhanda B. Warmth and affection: A Comparative study on soft skills and social skills among children. Int J Curr Microbiol Appl Sci. 2018; 7(06):922-4.

20. Gonçalves LD, Bottoli C. Paternidade: a construção do desejo paterno. Barbarói . 2016;(48):185-204.

21. Lombard N. 'Because they're a couple she should do what he says': Young People's justifications of violence: heterosexuality, gender and adulthood. J Gend Stud. 2016; 25(3): 241-53.

22. Correa AS. Interacionismo simbólico: raízes, críticas e perspectivas atuais. Rev Bras História Ciênc Soc. 2017; 9(17):176-200.

23. Follmer KB, Jones KS. Stereotype content and social distancing from employees with mental illness: The moderating roles of gender and social dominance orientation. J Appl Soc Psychol. 2017; 47(9):492504.

24. Albuquerque Netto L, Moura MA, Queiroz AB, Leite FM, Silva GF. Isolation of women in situation of violence by intimate partner: a social network condition. Esc Anna Nery. 2017;21(1):e20170007

25. Urrego Mendoza ZC, Coral G, Aristizabal Tobler CC, Bello Urrego AD, Bastidas Jacanamijoy L. Consideraciones éticas para la investigación en salud con pueblos indígenas de Colombia. Rev Salud Pública. 2017;19(6):827-32.

26. Acosta LM. Discriminação no tratamento jurídico recebido pelas mulheres nos códigos penais do século XIX. Rev Eletrôn Fac Direito Fr. 2015; 10(2):43-56.

27. Bentes HH. A "via crucis do corpo" da mulher: trajetos de violência na literatura brasileira sob a ótica dos direitos humanos das mulheres. ANAMORPHOSIS - Rev Int Direito e Lit. 2016; 2(1):147. 